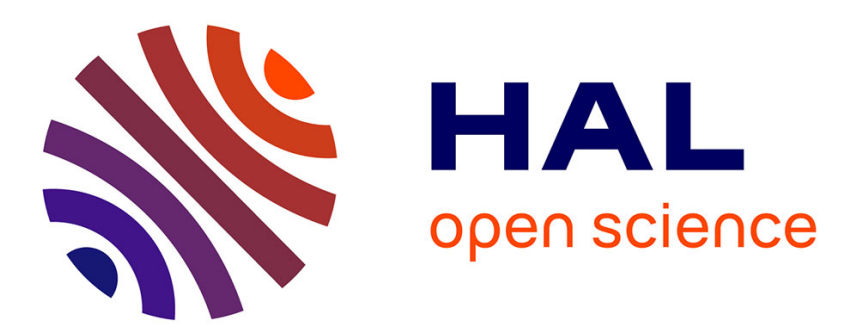

\title{
Microwave irradiation stimulated superconductivity and Josephson effect in cross-like film structures
}

\author{
Yu. G. Bevza, V.I. Karamushko, I.M. Dmitrenko
}

\section{To cite this version:}

Yu. G. Bevza, V.I. Karamushko, I.M. Dmitrenko. Microwave irradiation stimulated superconductivity and Josephson effect in cross-like film structures. Journal de Physique Lettres, 1979, 40 (5), pp.101104. 10.1051/jphyslet:01979004005010100 . jpa-00231576

\section{HAL Id: jpa-00231576 https://hal.science/jpa-00231576}

Submitted on 1 Jan 1979

HAL is a multi-disciplinary open access archive for the deposit and dissemination of scientific research documents, whether they are published or not. The documents may come from teaching and research institutions in France or abroad, or from public or private research centers.
L'archive ouverte pluridisciplinaire HAL, est destinée au dépôt et à la diffusion de documents scientifiques de niveau recherche, publiés ou non, émanant des établissements d'enseignement et de recherche français ou étrangers, des laboratoires publics ou privés. 


\title{
Microwave irradiation stimulated superconductivity and Josephson effect in cross-like film structures $\left({ }^{*}\right)$
}

\author{
Yu. G. Bevza, V. I. Karamushko and I. M. Dmitrenko \\ Physico-Technical Institute of Low Temperatures, UkrSSR \\ Academy of Sciences, 47, Lenin Prospekt, Kharkov, 310164, U.S.S.R. \\ (Reçu le 23 août 1978, révisé le 26 décembre 1978, accepté le 12 janvier 1979)
}

\begin{abstract}
Résumé. - On a réalisé l'étude expérimentale d'un film cruciforme. On a montré que l'apparition et la grandeur de la supraconductivité induite par le champ haute fréquence dépendent de la longueur du libre parcours moyen $(l=350-2000 \AA)$. L'homogénéité le long du film a été déterminée par comparaison avec la théorie de Galaiko [1], on constate un bon accord quantitatif. En présence du courant de contrôle dans la bande transversale, nous observons une augmentation relative de la supraconductivité induite. Dans ces conditions, le couplage de l'élément de Josephson cruciforme diminue, et des marches de Josephson apparaissent sur la caractéristique $V$-I.
\end{abstract}

\begin{abstract}
The cross-like film structure is studied experimentally. The occurrence and magnitude of the induced superconductivity effect in the microwave field are shown to depend on the mean free path $(l=350-2000 \AA)$. The homogeneity of a long strip was found through a comparison with Galaiko's theory [1] which gives quantitative agreement. As the control current $i$ passes through a transverse strip, the relative effect of induced superconductivity increases. The $i$ growth causes the coupling energy of the controlled cross-like element to decrease leading to microwave induced Josephson steps in the $I-V$ characteristics.
\end{abstract}

A number of papers have appeared recently, which concern the electrically controlled weak superconducting links [1-3]. They are based on different approaches to the construction of weak links and on different controlling mechanisms creating a weak link region. For our experiments [1] tin cross-like thin film structures were used. This type of sample is usually a single film in the form of a cross produced by a single evaporation. The results reported in this paper were obtained on the samples shown schematically in figure 3 (insert). The sample consists of a narrow longitudinal strip $60 \mu \mathrm{m}$ long and $2 \mu \mathrm{m}$ wide and a transverse film narrowing in the region of crossing (the narrowest site is about $1 \mu \mathrm{m}$ ). The film 800-1 $000 \AA$ thick was deposited onto a glass substrate maintained at $190-200 \mathrm{~K}$. The necessary sample geometry was provided photolithographically. The resistance ratio $R_{300} / R_{4.2}$ was usually within $8-22$ depending on the deposition rate, which varied from 20 to $80 \AA / \mathrm{s}$. Some samples were irradiated with Ar ions, the energy being up to $160 \mathrm{keV}$ and the dose up to $5 \times 10^{15} \mathrm{ion} / \mathrm{cm}^{2}$. In this case $R_{300} / R_{4.2}$

${ }^{*}$ ) This paper was presented at the LT 15 Conference as a postdeadline paper. was reduced and could reach a value of 4.5. If $R_{300} / R_{4.2}=4.5-22$, the mean free path $l$ is estimated to be $l=350-2000 \AA$ using the formula for a pure limit $l=l_{\mathrm{ph}}\left(R_{300} / R_{4.2}-1\right)$ where $l_{\mathrm{ph}}=95 \AA$ [4].

The experiments employing an electric control were aimed at of obtaining a lower order parameter in the region of the crossing (as compared to that for the rest of the film) due to the additional current component through the transverse film from an independent source. The experiment was planned with provision for microwave irradiation of the sample at a frequency $v=9-23 \mathrm{GHz}$. The substrate with the sample was placed within a waveguide separated by a $1 / 4$ wavelength from the short-circuiting piston so that the microwave field vector $\mathbf{E}$ was parallel to the transport current, i.e. the longitudinal film. The $I-V$ characteristics were registered with an $X-Y$ recorder for different irradiation powers $P$ and control currents $i$. The critical transport current was estimated from the voltage level $V=0.5 \mu \mathrm{V}$. The possibility of creating and controlling a short weak link region in a long homogeneous superconductor permits two physical problems which are of experimental interest to be studied under the external microwave irradiation. These are related to the stimulated superconductivity in the microwave field and the Josephson effect. 
In more detail, the questions are as follows : (1) Is the local inhomogeneity of the order parameter essential for microwave-induced superconductivity to occur ? and (2) How would the Josephson characteristics of the sample vary (e.g., the currentphase relation as a function of the order parameter minimum depth) ?

To solve the first problem, it is important to examine the film homogeneity in the absence of an electric control $(i=0)$. Several methods, the visual one included, were employed to examine the homogeneity of the longitudinal films in our cross-like structures. The $I-V$ characteristics of the $30 \mu \mathrm{m}$ arms of the cross were recorded. The comparison of the experimental $I-V$ curves and the calculations in terms of Galaiko's resistive state theory for long quasi-one-dimensional superconducting channels gave quantitative agreement [5]. Galaiko's theory enables a calculation to be made of the so-called second critical current $I_{\mathrm{c} 2}$ (the current at which a complete resistive-normal state transition occurs in the film) and the currents $I_{\mathrm{n}}$ and voltages $V_{\mathrm{n}}$ corresponding to the appearance of separate phase slip centres. $I_{\mathrm{c} 2}$ is treated experimentally as the current at which the $I-V$ curves were parallel to $R_{\mathrm{N}}$ (the normal resistivity of the film at $T>T_{\mathrm{c}}$ ). For some samples the measured and calculated $I_{\mathrm{c} 2}, I_{\mathrm{n}}$ and $V_{\mathrm{n}}$ were in good agreement $(\sim 5-10 \%)$. Another check on the sample homogeneity was accomplished by comparing the $I-V$ curves of two $30 \mu \mathrm{m}$ arms of the same sample at different $T$ with and without the external microwave irradiation. For the best samples the $I-V$ curves did not differ by more than $10 \%$. Thus, some of our samples were of sufficiently high homogeneity. It is important to note that under irradiation such samples display a growth of the critical current $I_{c}$ (the Dayem effect) [6], whereas our studies on tens of tin samples revealed no $T_{\mathrm{c}}$ growth. The $I_{\mathrm{c}}$ increase was observed for all the samples, though the temperature range of this effect was to a high degree dependent on the mean free path $l$. In samples of great $l$ (the pure case), $I_{\mathrm{c}}$ started to increase under irradiation at $T_{\mathrm{c}}$, while for $l=350 \AA$ the irradiation-caused growth of $I_{\mathrm{c}}$ was observed only at $T<3.74 \mathrm{~K}\left(T_{\mathrm{c}}=3.804 \mathrm{~K}\right)$. We believe that these specific features of the Dayem effect in long tin samples can be accounted for in terms of the numerical solution of Eliashberg's equation [7] :

$$
\begin{aligned}
& \frac{T_{\mathrm{c}}-T}{T_{\mathrm{c}}}-\frac{7 \zeta(3)}{8 \pi^{2}} \frac{\Delta^{2}}{\left(k T_{\mathrm{c}}\right)^{2}}-\frac{\pi}{2} \frac{\alpha}{k T_{\mathrm{c}}}- \\
& \quad-0.11 \frac{\pi}{2}\left(\frac{\hbar \omega}{k T_{\mathrm{c}}}\right)^{2} \frac{\alpha}{\gamma}=-\frac{\alpha}{\gamma} \frac{\hbar \omega}{4 k T_{\mathrm{c}}} \mathcal{G}
\end{aligned}
$$

where $\alpha=\frac{1}{3} \frac{v_{\mathrm{F}} l e^{2} A_{\omega}^{2}}{\hbar c^{2}}, A_{\omega}$ is the microwave field amplitude, $\gamma=\frac{\hbar}{\tau_{\varepsilon}}, \tau_{\varepsilon}$ is the inelastic relaxation time, $\Delta$ the energy gap, $v_{\mathrm{F}}$ the Fermi velocity and $\mathcal{G}$ the function related to the non-equilibrium quasi-particle distribution

$$
\mathcal{G}=-\frac{8 k T_{\mathrm{c}}}{\hbar \omega} \frac{\gamma}{\alpha} \int_{\Delta}^{\infty} \frac{\mathrm{d} \varepsilon}{\left(\varepsilon^{2}-\Delta^{2}\right)^{1 / 2}} n_{1}(\varepsilon),
$$

where $n_{1}(\varepsilon)$ is the deviation from the equilibrium distribution. The function $\mathcal{G}(\Delta)$ was numerically computed using Eliashberg's expression for $n_{1}(\varepsilon)$ [8]. Equation (1) was solved graphically at different $T$ and $\alpha / \gamma$ through equating the left hand side of eq. (1) and the computed function $\mathcal{G}(\Delta)$. The calculated temperature dependence of $(\Delta / \hbar \omega)^{2}$ for tin at different $\alpha / \gamma$ is shown in figure 1 . The irradiation frequency

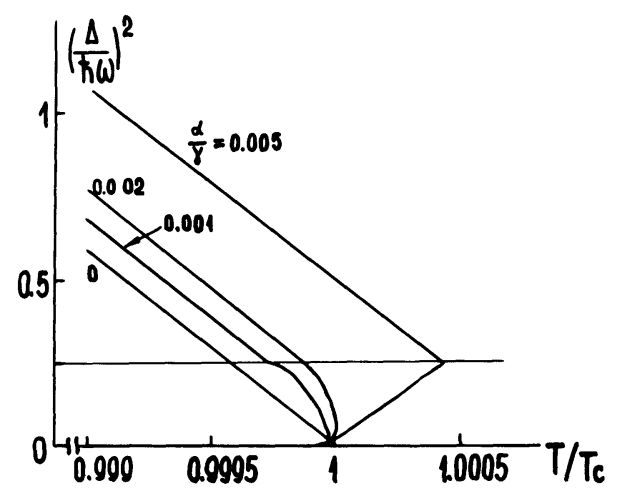

Fig. 1. - Results of numerical calculation of Eliashberg's equation for tin $\left(\tau_{\varepsilon}=2 \times 10^{-10} \mathrm{~s}\right)$ at external radiation frequency $v=10^{10} \mathrm{~Hz}$.

$\omega / 2 \pi$ is taken to be $10 \mathrm{GHz}, \tau_{\varepsilon}=2 \times 10^{-10} \mathrm{~s}$. As follows from figure 1, irradiation causes no increase in $T_{\mathrm{c}}$ for $\alpha / \gamma<0.002$ and the relative gain in $T_{\mathrm{c}}$ for $\alpha / \gamma=0.005$ amounts only to $4 \times 10^{-4}$, which is practically unobservable. For the optimum power $P_{\mathrm{m}}$ corresponding to the maximum $I_{\mathrm{c}}, \alpha / \gamma$ may be estimated experimentally. With small $l$ near $T_{\mathrm{c}}$, where the Dayem effect is absent, the case similar to the classical detection is observed. The dependence $I_{c}(P)$ is helpful in finding an approximate matching, i.e. the relation between $P$ and the microwave current amplitude. Then with $R_{\mathrm{N}} \simeq 1 \mathrm{ohm}$ the film inductances $L \simeq 10^{-10} \mathrm{H}$ for $P_{\mathrm{m}}$ and $\alpha / \gamma$ were about 0.001 ( $l=$ maximum). It is thus seen that the $T_{\mathrm{c}}$ increase in tin films under irradiation is rather questionable.

According to eq. (1), $I_{\mathrm{c}}$ should continuously increase with increasing $P$. Experimentally, $I_{\mathrm{c}}$ reaches its peak at some $P_{\mathrm{m}}$. With a further $P$ growth $I_{\mathrm{c}}$ decreases, very rapidly at the end - almost in a jump-like manner. In the $P_{\mathrm{m}}$ region the $I_{\mathrm{c}}$ hysteresis starts to appear even near $T_{\mathrm{c}}$, much before the thermal hysteresis in the irradiationless $I-V$ curves. A sharp reduction of $I_{c}(P)$ occurs as the reverse critical current goes to zero.

We have attempted to make allowance for the classical detection, which means that the experimentally observed critical current is $I_{\mathrm{ce}}=I_{\mathrm{c}}-I_{\mathrm{a}}\left(I_{\mathrm{a}}\right.$ is the microwave current amplitude) rather than $I_{\mathrm{c}}$ found from Eliashberg's theory. As follows from eq. (1), 
at $T<T_{\mathrm{c}}, \Delta^{2}$ is well approximated by its linear dependence on $\left(T_{\mathrm{c}}-T\right)$ and $\alpha / \gamma$. For the case in figure 1

$$
\left(\frac{\Delta}{\hbar \omega}\right)^{2}=\left(\frac{\Delta_{0}}{\hbar \omega}\right)^{2}+\frac{\alpha}{\gamma}\left(T_{\mathrm{c}}-T\right) \cdot 10^{5}
$$

where $\Delta_{0}$ is the gap in the absence of irradiation. Assuming $I_{\mathrm{c}} \propto \Delta^{3}$ and using eq. (2), a simple analytical expression is readily obtained for $I_{\text {ce }}\left(I_{\mathrm{a}}\right)$. The microwave current $I_{\mathrm{am}}$ corresponding to the maximum of the Dayem effect can be found from $\frac{\mathrm{d} I_{\mathrm{ce}}}{\mathrm{d} I_{\mathrm{a}}}=0$. The temperature $T_{1}$, at which the $I_{\mathrm{c}}(P)$ maximum is first seen (the first observation of the $I_{\mathrm{c}}$ growth under irradiation), is determined by the condition $I_{\mathrm{ce}}>I_{\mathrm{c} 0} \quad\left(I_{\mathrm{c} 0}\right.$ is the irradiationless critical current $)$ with $I_{\mathrm{am}}$ substituted into $I_{\mathrm{ce}}\left(I_{\mathrm{a}}\right)$. For $l=350 \AA$, $\left(T_{\mathrm{c}}-T_{1}\right)=0.065 \mathrm{~K}$ (calculation) and $0.064 \mathrm{~K}$ (experiment), for $l=2000 \AA\left(T_{\mathrm{c}}-T_{1}\right)=0.01 \mathrm{~K}$ (calculation) and $\sim 0 \mathrm{~K}$ (experiment).

With a non-zero control current $I_{\mathrm{ce}} / I_{\mathrm{c} 0}$, the relative value of the stimulation effect (where it exists) increases. It is possible that with the weak link region available, some mechanism of smearing the order parameter should become operative in addition to Eliashberg's mechanism (see Ref. [9]). In our samples the weak link was produced by additional pair destruction in the region of crossing $[1,10]$ as the transition of the controlling transverse film into the resistive state occurs. The peculiar feature of our sample is its modulation characteristic, i.e. the dependence of the critical transport current $I_{c}$ on the control current $i$. Figure 2 shows the modulation curves taken on one of the samples at different temperatures : a) $3.82 \mathrm{~K}, b) 3.81 \mathrm{~K}, c) 3.8 \mathrm{~K}, d) 3.79 \mathrm{~K}$, e) $3.78 \mathrm{~K}, T_{\mathrm{c}}=3.83 \mathrm{~K}$. The principal qualitative findings assert the possibility of a smooth and reversible control of the critical transport current $I_{\mathrm{c}}$. It is also seen that small control currents $i$ do not affect $I_{\mathrm{c}}$. The control begins at certain $i_{\mathrm{c}}^{\prime}(T)$ shown by arrows in figure $2 a$. Figure $2 b$ presents the correlation between the threshold current $i_{\mathrm{c}}^{\prime}$ and the control film critical current $i_{\mathrm{c}}$. Near $T_{\mathrm{c}}$ (the first two points correspond to $3.82 \mathrm{~K}$ and $3.81 \mathrm{~K}$, respectively) the currents $i_{\mathrm{c}}^{\prime}$ and $i_{\mathrm{c}}$ coincide, at lower temperatures $i_{\mathrm{c}}^{\prime}$ appreciably exceeds $i_{\mathrm{c}}$. This situation differs essentially from the case of control using the quasi-particle injection [2], where the control current is weakly $T$-dependent.

The modulation characteristics (at $i>i_{\mathrm{c}}^{\prime}$ ) of the cross-like samples (near $T_{\mathrm{c}}$ ) were calculated using the Ginzburg-Landau equation [1]

$$
\frac{\mathrm{d}^{2} f}{\mathrm{~d} x^{2}}-\frac{j^{2}+\left(\gamma_{1} j_{\perp}\right)^{2}}{f^{3}}+f-f^{3}=0
$$
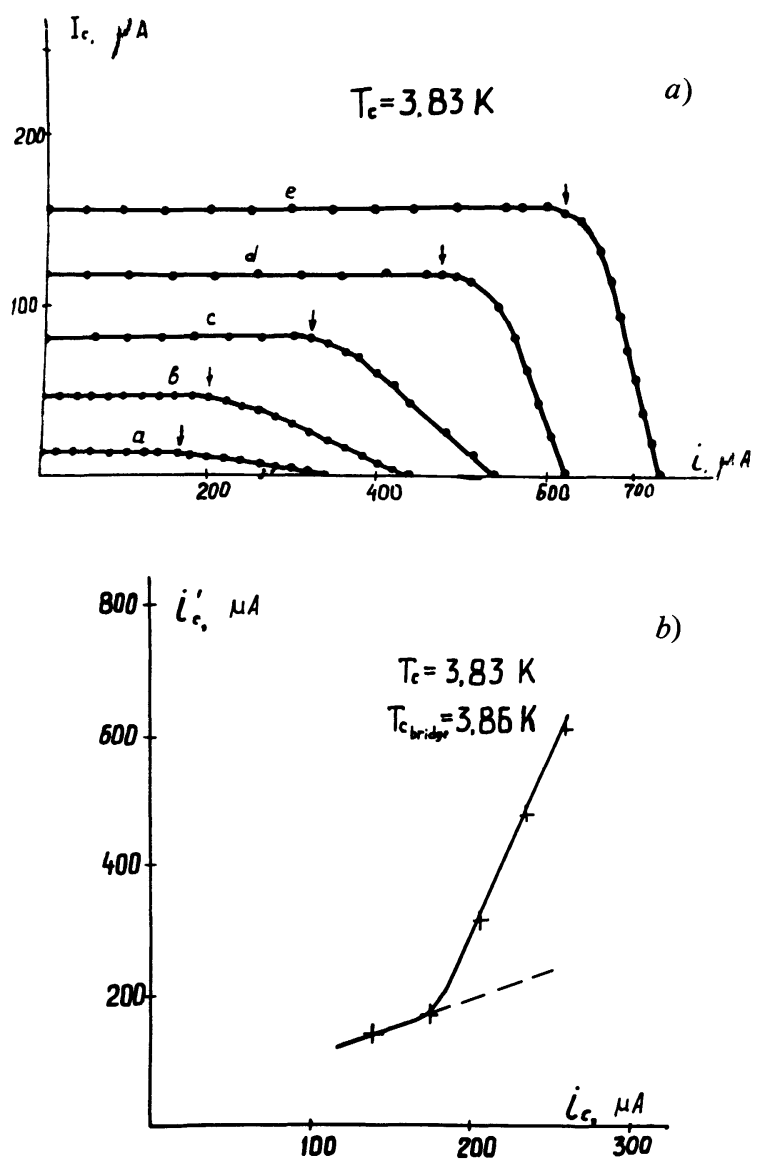

Fig. 2. $-a$ ) Modulation curves $I_{\mathrm{c}}(i)$ at various temperatures : $a: 3.82 \mathrm{~K}, b: 3.81 \mathrm{~K}, c: 3.80 \mathrm{~K}, d: 3.79 \mathrm{~K}, e: 3.78 \mathrm{~K}, T_{\mathrm{c}}=3.83 \mathrm{~K}$. $b)$ Threshold current $i_{\mathrm{c}}^{\prime}$ as a function of control film critical current $i_{\mathrm{c}}$ for the same sample. Points (from left to right) correspond to temperatures $3.82,3.81,3.80,3.79,3.78 \mathrm{~K}$.

Here $f(x)$ is the modulus of the order parameter in relative units, $f(x)=\Delta(x) / \Delta_{0}, \Delta_{0}$ is the solution of the Ginzburg-Landau equation for a homogeneous film, $j$ the transport (longitudinal) current density, $j_{\perp}$ the control current density, $\gamma_{1}$ the coefficient accounting for the broadening of the control current lines in the region of crossing. For $i>i_{\mathrm{c}}^{\prime}$ the calculated and experimental modulation characteristics show good agreement, when $\gamma_{1}$ is used as a fitting parameter

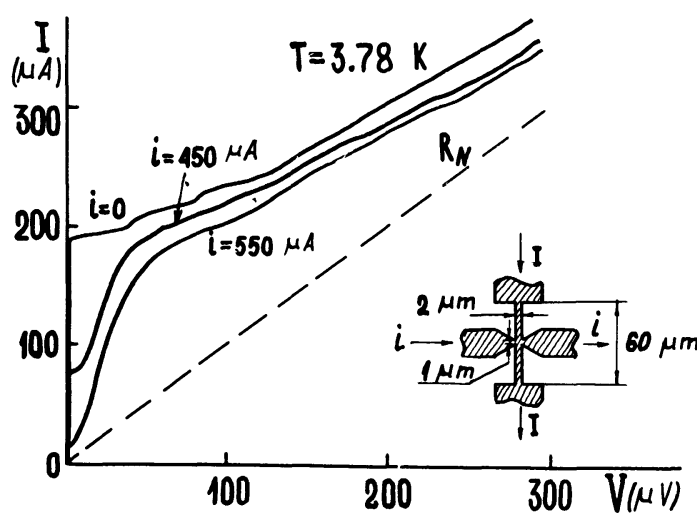

Fig. 3. - I-V curves of cross-like sample at various control currents. The sample configuration is shown in the insert. 
(the fitting was usually performed at the point where the critical transport current reduces to zero), $\gamma_{1} \approx W_{2} / W_{1}$ where $W_{1}$ and $W_{2}$ are the transport film width and the narrowest width of the control film, respectively.

Figure 3 presents $I-V$ curves for a cross-like sample at different $i$. The $i=0$ curve displays some steps corresponding to the phase slip centres appearing in the film. With $i>i_{\mathrm{c}}^{\prime}$, region appears in the low voltage part of the $I-V$ curve, which is related to the resistivity of the artificially created weak link. At $T / T_{\mathrm{c}}>0.99$ this region displays microwave-induced steps. As $i$ increases, the coupling energy of the controlled Josephson element decreases, and, as seen in figure 4 , the power dependence of the first step height approaches the standard Bessel dependence.

To conclude, it should be noted that we observed the Dayem effect in long narrow films of high homogeneity. The effect is well described by Eliashberg's theory. When a weak link is created, the relative

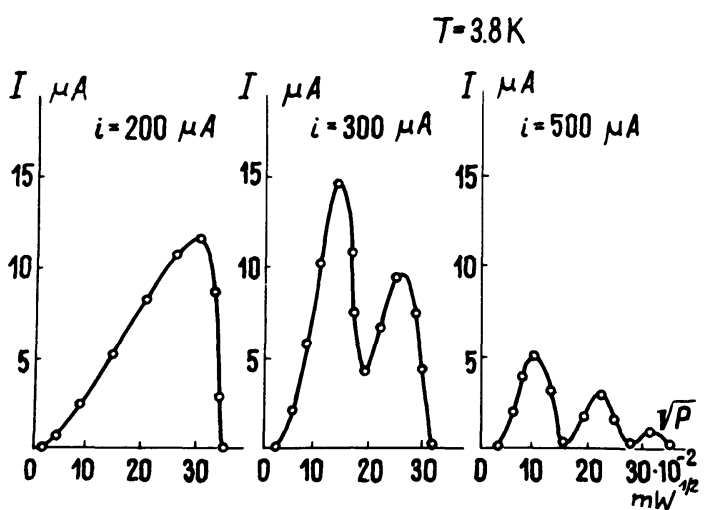

Fig. 4. - Microwave radiation power dependence of the first Josephson step magnitude at various $i$.

magnitude of the effect increases. Near $T_{\mathrm{c}}$ our electrically controlled weak links revealed the non-stationary Josephson effect whose characteristics are governed by the value of control current.

\section{References}

[1] Bevza, Yu. G., Tsakh, G. G., Karamushko, V. I., DmitrenKO, I. M., « Effekt vozrastaniya kriticheskogo toka v SVCh pole na krestoobraznykh sverkhprovodyashchikh tonkoplenochnykh mostikakh ", Pisma v Zh. Tekhn. Fiz. 2 (1976) 367-371.

Bevza, Yu. G., Karamushko, V. I. and Dmitrenko, I. M., "Cross-like film structures. Microwave irradiation stimulated superconductivity and Josephson effect ", J. Physique Colloq. 39 (1978) C6-537-538.

[2] Ting-Wah Wong, Yen, J. T. C., Langenberg, D. N., " Quasiparticle-injection induced superconductivity », Phys. Rev. Lett. 37 (1976) 150-153.

[3] Pals, J. A., « Microwave-enhanced critical currents in superconducting Al strips with local injection of electrons ", Phys. Lett. 61A (1977) 275-278.

[4] AndratskiI, V. P., Grundel, L. M., Gubankov, V. N., Pavlov, N. B., «O razrushenii tokom sverkhprovodimosti v tonkikh uzkikh plenkakh ", Zh. Eksp. Teor. Fiz. 65 (1973) 1591-1599.
[5] Galaiko, V. P., " Kinetic theory of resistive states and electric oscillations in superconducting channels ", J. Low Temp. Phys. 26 (1977) 483-500.

[6] It will be recalled that for $5 \mathrm{~m}$-films the Dayem effect was observed only in artificially created weak link (see Ref. [1])

[7] KlapwiJk, T. M., VAN DEN BerGH, J. N., MoOIJ, J. E., « Radiation-stimulated superconductivity », J. Low Temp. Phys. 26 (1977) 385-405.

[8] Ivlev, B. I., Lisitsyn, S. G., Eliashberg, G. M., " Nonequilibrium excitations in superconductors in high-frequency fields », J. Low Temp. Phys. 10 (1973) 449-468.

[9] LindeHOF, P. E., " Microwave-enhanced critical currents in superconducting microbridges explained by the electricfield induced quasi-particle pair inequilibrium ", Solid State Commun. 18 (1976) 283-286.

[10] Kulik, I. O., Omelyanchuk, A. N., Kelman, E. A., "Uppavlyaemye tokom sverkhprovodyashchie kontakty", Fiz. Nizk. Temp. 3 (1977) 1107-1117. 